\title{
Annual Conference: Meetings for all minds
}

\section{Part 2 of our Annual Conference bighlights}

\section{Librarians vs. scholars}

“Today's Libraries Face Tomorrow's Scholars: Faults and Fissures," sponsored by the Rare Books and Manuscripts Section, explored the values librarians and scholars share as well as the different bits of turf on which they stand.

James P. Michalko, president of RLG, Inc., discussed issues related to the recent RLG publication Preferred Futures for Libraries. The preferred future strongly shared by library directors and university provosts includes a multimedia workstation with access to everything and everyone online. Michalko did not see this in anyone's future, and he cited a recent graffiti: a triangle with one word at each comer - "good," "fast," "cheap" - and the caption "pick any two." An appropriate workstation for humanists would be very complex, no one knows bow to build it, and the relatively small number of dollars supporting humanistic research will not attract commercial development.

At the same time, Michalko warned that the competition between disciplines for scarce dollars is real and will grow more vigorous as the number of electronic products expands and that humanists and librarians would be wise to collaborate in setting priorities and cooperate in explaining them to the general public if they hope to impact national decisions.

This theme was picked up by Phyllis Franklin, executive director of the Modern Language Association, who reported the responses to questions she had posed to more than 300 scholars. From this material Franklin concluded that "the common ground between librarians and scholars has shifted: library administrators have changed while humanistic scholars have remained much the same." While her respondents urged "full steam ahead into the electronic era," three deep concerns emerged. First, that microfilming of brittle books has inadvertently come to be seen as a model for handling other materials as well. Second, Franklin asked that we imagine books will be published until 2055 and no longer; what should be preserved? Scholars want to preserve as complete a record of the 600-year print era as possible and resist any attempts to preserve that record in other formats or in a relatively small number of repositories. Third, even the most dedicated literary theorists spoke eloquently to the "materiality of text" and the impossibility of separating content from format. Franklin too saw collaboration as an urgent need.-Sidney F. Huttner, University of Tulsa

... be cited a recent graffiti: a triangle with one word at each corner- "good," "fast," "cheap"and the caption "pick any two."

\section{The barriers to information}

"Issues in Sci-Tech Information: Librarians' Right to Know" presented by the Science and Technology Section focused on information barriers confronted by librarians and information seekers.

Jane Bortnick of the Congressional Research Service discussed trends in sci-tech information and resulting policy dilemmas including public access, intellectual property rights, pricing formulae, budget constraints, changing institutional roles, and the need for revising existing laws and regulations. With policy being made in the midst of much uncertainty and the government eyeing information as a source of revenue, information professionals are understandably nervous.

Michael Fry of the University of CaliforniaDavis described the misuse of information in the Exxon Valdez incident as illustrative of "the fundamental conflict between those involved in litigation and science." Research assessing environmental damage was overseen by government officials, attorneys, and others with vested interests. 
Tracey Cosgrove of the Planetree Health Resources Center, cited barriers confronted daily by those needing medical information including cultural, sexual, and racial biases; language differences; problems with NLM subject headings; and collection restrictions.

Other perspectives were provided by Ron Rodrigues of Dialog and Ronald Akie of Faxon. Rodrigues gave Dialog's criteria for selecting or rejecting databases. Akie introduced his talk on the publishing situation in Eastern Europe as "a travel guide through utter chaos."-Julia Zimmerman, Georgia Institute of Technology

\section{"Cinema Paradise: Movies, Libraries, and European Culture"}

This Western European Specialists Section program informed its audience of 275 about current European and American film production, current scholarship in film, and archival preservation and library collections for film study.

Steve Hanson, University of Southern California Cinema-Television Library, illustrated with clips how American movies, and the "global" and "Eurofilm," have supplanted the national films of European countries. He predicted that European national films will survive for a few years but they will be fewer in number and more expensive to make. Librarians will have a harder time acquiring them for their collections.

Nancy Goldman, Pacific Film Archive, talked on the costs of maintaining national film archives to preserve national cinemas (it might exceed $\$ 40,000$ simply to keep a negative and positive print of one film). Her comments on film preservation included that over 70 percent of all silent films no longer exist in any form.

Anne Schlosser, Warner Bros. Research Library, characterized two types of film librariesprint: collections of film prints or stock footage; and paper: materials on paper about film. She reviewed the published and unpublished materials - mostly paperwork that accompanies the making of films - they collect. With a handout she outlined the strengths of selected American institutions and notable European collections.Marcia Pankake, University of Minnesota

\section{Issues in medical anthropology}

In "Medical Anthropology: Choices and Challenges," sponsored by the Anthropology and Sociology Section and the Science and Technology Section, M. Margaret Clark described the evolution of medical anthropology which 1) began as a study of the health practices of indigenous populations; 2) was expanded to Western industrialized nations in response to the frequent failure of public health programs among minority groups; and 3) by the early 1960 s came to include the study of health practices and policies in their many diverse aspects.

Barbara A. Koenig discussed the anthropology of biomedicine and mentioned the book Laboratory Life: The Social Construction of Scientific Factors (Latour, Woolgar, 1979) as seminal in breaking the myth of the positivism of science. Medical anthropologists work to bring daily experience to bear on the theoretical issues of medicine.

In a study of gay men in San Francisco who tested HIV positive, speaker Stephen Eyre identified four varieties of coping mechanisms: 1) wholistic healing; 2) a 12-step program, somewhat like that of Alcoholics Anonymous; 3) activism; and 4) treatment advocacy. Each approach provides a sense of control, involves judgment, and offers the means for retribution.

Daniel T. Richards discussed the complexities of collection development. Librarians must know clientele needs, know their local collection, acquire and preserve materials in a wide range of formats, share resources, and foster cooperative collection development. The discussion which followed the program centered on the failure of the major medical indexes to cover the journal literature of medical anthropology.-James W. Williams, University of Illinois, Urbana-Cbampaign

\section{Access and technology}

In the College Library Section program "Alternatives to Collection Ownership: College Library Implications and Applications," keynoter Ralph Alberico, University of Texas at Austin, challenged college librarians to view both ownership and electronic delivery as forms of access since today's library comprises a set of documents and a set of services, not just one or the other. Paying for information is now both a matter of paying for packages stored on-site and for other forms of access, which together equal a library's delivery capacity. Action steps for maintaining effectiveness in today's technologically advanced environment include building an infrastructure to actualize electronic transfer of information, sceking alternative forms of budgeting, and experimenting with available delivery systems.

Robert Adams (Wesleyan University) and Nancy Taylor (Earlham College) presented consortial and bibliographic instruction perspectives on the topic. Paul Peters (Coalition for 
Networked Information) comforted the group with a whimsical but probing look at the evolutionary process of change in the electronic access arena, elaborating on the Paleo-electronic, Mesoelectronic, and Neoelectronic Ages.-Jonathan D. Lauer, Messiab College

\section{Copyright Law: Beauty and the Beast}

In "Developing and Implementing a Copyright Policy: Institutional Issues for Academic Libraries," the ACRL Copyright Committee program, keynote speaker Kenneth Crews, associate professor of business law at San Jose State University, used a Beauty and the Beast analogy to articulate his views. Too often interpretation of the Copyright Law reflects its "beast" qualities: fearsome and domineering. A more "beauty"-like approach would use the flexibility in the law to bring experience and judgment into determining what is fair use in a specific situation.

David Carlson, director of Triangle Research Library Network, related his previous experience in developing a

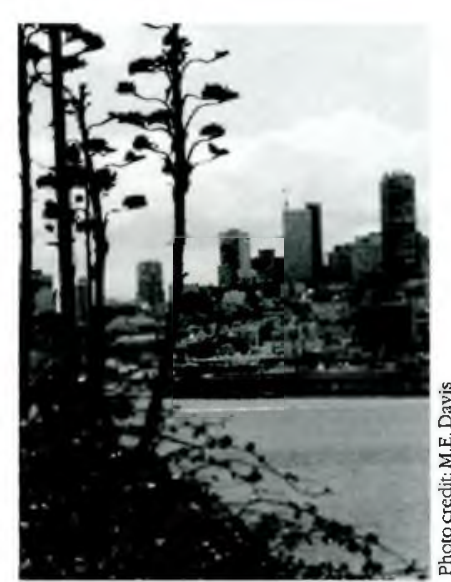

A view of San Francisco from Alcatraz Island
Library Program at the U.S. Institute of Peace, gave an overview of the nonprofit world by pointing out that "the voluntary sector is an inherent part of American life." In 1990 there were 983,000 nonprofit organizations in the U.S., representing a 6.8 percent share of the total national income and employing 10.4 percent of the working population. While these statistics are impressive, Bohlen and the other speakers emphasized that the nonprofit sector is too small to take the place of government action.

Kirke Wilson, executive director of the Rosenberg Foundation, described the complex world of foundations, which play a secondary role in the nonprofit sector since only $10 \%$ of the money comes from foundations, while $90 \%$ comes from individuals. Foundations can be categorized by typefamily, community, or corporate-or by size-small, medium, or large.

Regardless of type or size, it is important for applicants to be familiar with the mission of the foundation. The majority of rejections for funding by a foundation are a result of the applicants' not understanding the kind of work the foundation supports.

Nora Silver, director of the Volunteer Project, discussed the many aspects of volunteer work. Fifty-four percent of all adults volunteer four hours per week, with more people volunteering than voting. Volunteer work involves some definite "dos" -and "don'ts." Volunteers can be involved in fundraising, special events, tutoring, visiting the elderly, etc. Volunteers should not take jobs from paid workers, and they can't provide the continuity that paid staff provides.

Roberta Steiner, director of the San Francisco office of the Foundation Center, described the center's work and publications. In addition to its specialized publications, which include directories, a grants index, guidebooks, and specialized management books, the center also has four main offices and 108 cooperative offices in libraries nationwide. These offices offer an array of services including fee-based reference and consultant services.-Sever Bordeianu, University of New Mexico, Albuquerque 

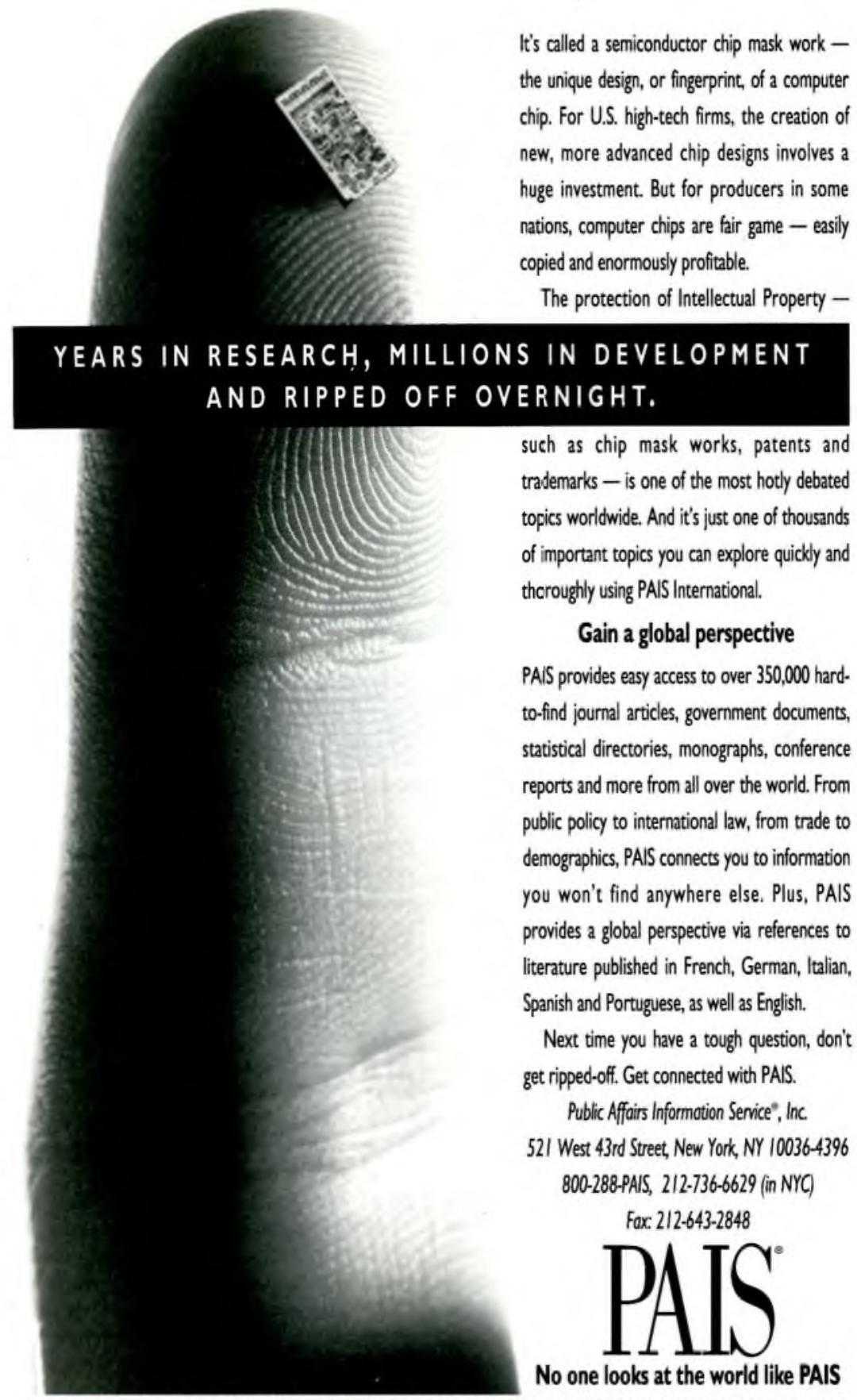

such as chip mask works, patents and trademarks - is one of the most hotly debated topics worldwide. And it's just one of thousands of important topics you can explore quickly and thcroughly using PAIS International.

\section{Gain a global perspective}

PAIS provides easy access to over 350,000 hardto-find journal articles, government documents, statistical directories, monographs, conference reports and more from all over the world. From public policy to international law, from trade to demographics, PAIS connects you to information you won't find anywhere else. Plus, PAIS provides a global perspective via references to literature published in French, German, Italian, Spanish and Portuguese, as well as English.

Next time you have a tough question, don't get ripped-off. Get connected with PAIS.

Public Affairs Informotion Service", Inc.

521 West 43rd Street, New York, NY 10036-4396 800-288-PAIS, $212-736-6629$ (in NYC) Fox. 212-643-2848

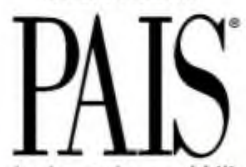

No one looks at the world like PAIS

In Print: PAIS INTERNATIONAL IN PRINT * PAIS SUBJECT HEADINGS Online Through: BRS - DATA-STAR • DIALOG • OCLC - RLG On CD-ROM: PAIS ON CD.ROM + PAIS INTERNATIONAL ON SILVER PLATTER On Magnetic Tape: CONTACT PAIS FOR INFORMATION 